\title{
Comparison of bile salt/phosphatidylcholine mixed micelles in solubilization to sterols and stability
}

This article was published in the following Dove Press journal:

Drug Design, Development and Therapy

17 November 2016

Number of times this article has been viewed

\section{Qin Guol,* \\ Jie Cai ${ }^{1,2, *}$ \\ Pengyu $\mathrm{Li}^{\prime}$ \\ Dongling $\mathrm{Xu}^{\prime}$ \\ Xiaomin $\mathrm{Ni}^{\prime}$ \\ Hui Wen ${ }^{3}$ \\ Dan Liu ${ }^{3}$ \\ Suizhen $\operatorname{Lin}^{3}$ \\ Haiyan $\mathrm{Hu}^{\prime}$}

'School of Pharmaceutical Sciences, Sun Yat-sen University, ${ }^{2}$ Guangzhou

First People's Hospital, Guangzhou Medical University, ${ }^{3}$ Guangzhou

Cellprotek Pharmaceutical Co., Ltd., Science Park, Guangzhou, People's

Republic of China

*These authors contributed equally to this work
Correspondence: Haiyan Hu

School of Pharmaceutical Sciences, Sun Yat-sen University, I 32 Waihuan East Road, University Town, Guangzhou 510006, People's Republic of China $\mathrm{Tel} / \mathrm{fax}+862039336119$

Email Isshhy@mail.sysu.edu.cn

\begin{abstract}
Androst-3 $\beta, 5 \alpha, 6 \beta$-triol (Triol) is a promising neuroprotective agent, but its poor solubility restricts its development into parenteral preparations. In this study, Triol is significantly solubilized by bile salt/phosphatidylcholine mixed micelles (BS/PC-MM). All BS/PC-MM systems are tested to remarkably improve the drug solubility with various stabilities after drug loading. Among them, the sodium glycocholate (SGC)/egg phosphatidylcholine (EPC) system with 2:1 ratio in weight and the total concentration of SGC and EPC of $100 \mathrm{mg} / \mathrm{mL}$ is proved to produce stable mixed micelles with high drug loading. It is found that the stability of drug-loaded mixed micelles is quite different, which might be related to the change in critical micelle concentration (CMC) after incorporating drugs. SGC/EPC and SGC/soya phosphatidylcholine (SPC) remain transparent under accelerated conditions and manifest a decreased CMC (dropping from 0.105 to $0.056 \mathrm{mg} / \mathrm{mL}$ and from 0.067 to $0.024 \mathrm{mg} / \mathrm{mL}$, respectively). In contrast, swine bile acid-sodium salt (SBA-Na)/PC and sodium deoxycholate (SDC)/PC are accompanied by drug precipitation and reached the maximum $\mathrm{CMC}$ on the first and the third days, respectively. Interestingly, the variation of $\mathrm{CMC}$ under accelerated testing conditions highly matches the drug-precipitating event in the primary stability experiment. In brief, the bile salt/phosphatidylcholine system exists as a potential strategy of improving sterol drug solubility. CMC variation under accelerated testing conditions might be a simple and easy method to predict the stability of drug-loaded mixed micelles.
\end{abstract}

Keywords: bile salt/phosphatidylcholine, mixed micelles, sterols, solubilizing, stability

\section{Introduction}

Androst-3 $\beta, 5 \alpha, 6 \beta$-triol' (Triol, Figure 1) is considered as a promising neuroprotective candidate functioning via negative modulation of $N$-methyl-D-aspartic acid receptors. ${ }^{1}$ However, its poor solubility in water restricts its development into parenteral preparations. Although Triol is freely soluble in ethanol, propylene glycol, PEG4000 and their mixed solvents, significant crystallization occurs when it is diluted with water or saline, which makes it difficult to use in design of injection preparations for emergency therapy. Recently, bile salt/phosphatidylcholine mixed micelles (BS/PC-MM), developed as a preferable vehicle for poorly soluble drugs, has overcome many drawbacks of other vehicles such as co-solvents that are reported to cause severe irritation and precipitation upon aqueous dilution. ${ }^{2,3}$ The BS/PC-MM system has been widely accepted as a solubilizing system due to its capacity of drug solubilization and biocompatibility. ${ }^{4-8}$ However, BS/PC-MM system was rarely reported to solubilize sterols. In the BS/PC-MM system, the bile salts (BSs) interact with the aqueous solvent through their hydrophilic surfaces and combine with the hydrophobic tail of phosphatidylcholine (PC) via hydrophobic surfaces. ${ }^{9}{ }^{10}$ Drugs were reported to bind to BSs either in the palisade layer or in the micellar core. ${ }^{11}$ Although solubilizing capacity is a fundamental consideration for BS/PC-MM system, its stability 
A

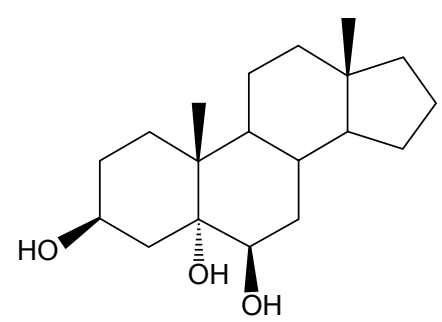

C

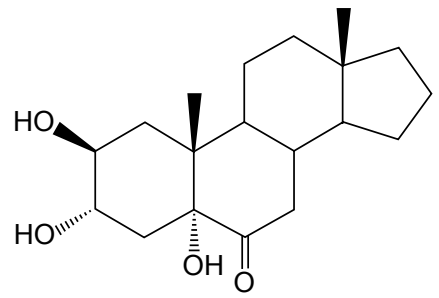

B

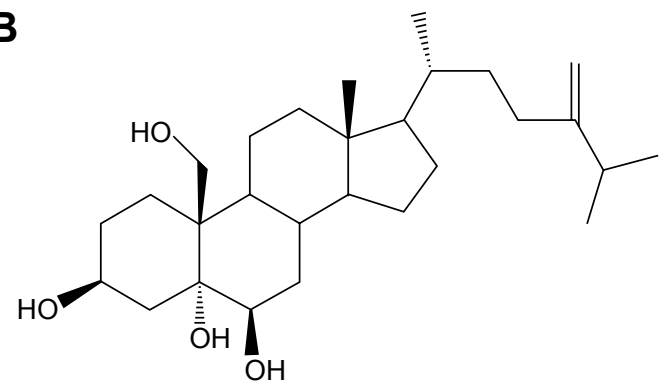

D

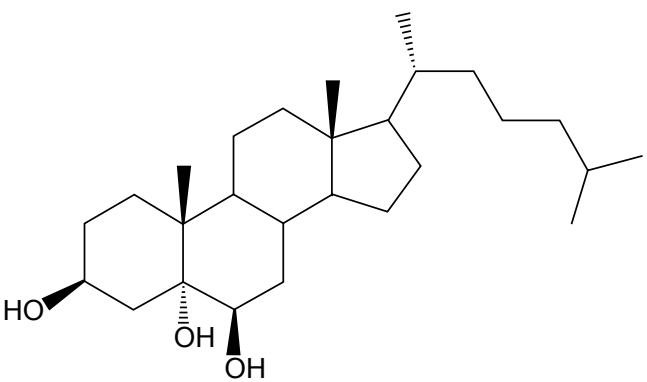

Figure I Molecular structures of synthesized sterols.

Notes: (A) Triol; (B) YC-I; (C) YC-I0; (D) YC-5.

Abbreviations: Triol, Androst-3 $\beta, 5 \alpha, 6 \beta$-triol; YC-I, Cholest-24-ene-3 $\beta, 5 \alpha, 6 \beta$, I 9-tetrol; YC-I0, Androst-2 $\beta, 3 \alpha, 5 \alpha$-trihydroxy-6-one; YC-5, Cholest-3 $\beta, 5 \alpha, 6 \beta$-triol

after drug loading is equally important. For example, BS/PC-MM system solubilized lorazepam has a short shelf life of 2 weeks at $25^{\circ} \mathrm{C}$. $^{5}$ Besides, the drug-loaded mixed micelles (MM) are proposed to be kept in dry form until usage. $^{4}$ Therefore, the inherent stability of micelles remains a great challenge and needs to be further investigated.

Critical micelle concentration (CMC), a key parameter characterizing a micelle, indicates the minimum concentration of a surfactant in a solution that is required to form the micelles. ${ }^{12,13} \mathrm{CMC}$ is an important indicator related to solubilization of MM. Generally, lower CMC indicates higher micelle-forming capacity and thus greater solubilizing capacity. The variation in CMC may partially reflect the solubilizing capacity and stability of MM.

The objective of this work is to study the characteristics of different BS/PC-MM systems for sterol drug solubilization and to investigate the stability of different drug-loaded BS/ PC-MM systems. This could provide new guidance to utilize suitable BS/PC-MM systems to enhance dissolving of insoluble sterol drugs while maintaining long-term stability.

\section{Materials and methods}

\section{Materials}

Triol, YC-1 (Cholest-24-ene-3 $\beta, 5 \alpha, 6 \beta, 19$-tetrol), YC-5 (Cholest-3 $\beta, 5 \alpha, 6 \beta$-triol), and YC-10 (Androst- $2 \beta, 3 \alpha, 5 \alpha$ trihydroxy-6-one) were kindly provided by Guangzhou Cellprotek Pharmaceutical Co., Ltd (Guangzhou, People's Republic of China). Egg phosphatidylcholine (EPC) was purchased from Kewpie Corporation (Tokyo, Japan). Soya phosphatidylcholine (SPC) was supplied by Lipoid (Ludwigshafen, Germany). Sodium deoxycholate (SDC) and sodium glycocholate (SGC) were obtained from Aladdin (Shanghai, China). Swine bile acid-sodium salt (SBA-Na) was purchased from Jianglaibio (Shanghai, China). Methanol for high-performance liquid chromatography (HPLC) use is of chromatographical grade. Water was double-distilled. All other reagents were of analytical grade.

\section{Preparation of drug-loaded micelles}

MM were prepared by the co-precipitation method as previously described, with modifications. ${ }^{11}$ Briefly, BS and $\mathrm{PC}$ with required weight ratios were dissolved in ethanol in a round-bottomed flask by ultrasound to prepare transparent blank MM. Excess amount of drug was then added in and treated by ultrasound for $10 \mathrm{~min}$. A film was formed after evaporation of the ethanol at $60^{\circ} \mathrm{C}$ by Rotavapor (RV 10 basic V-C; IKA, Staufen, Germany). The residue films were dispersed in a given amount of water (at room temperature) up to the required concentrations and subsequently centrifuged at $13,000 \mathrm{rpm}$ and $25^{\circ} \mathrm{C}$ (Sorvall Legend Mach1.6; Thermo Fisher Scientific, Waltham, MA, USA) for $5 \mathrm{~min}$. The supernatant was filtered with a $0.22 \mu \mathrm{m}$ Millipore filter to remove the excess amounts of drug and give the saturated drug-loaded MM. EPC and SPC were combined with three types of BSs (SGC, SDC and SBA-Na), respectively, to develop six kinds of drug-loaded MM. 


\section{Determination of drug solubility in different micelle systems}

The solubility of Triol in the six types of BS/PC-MM systems was measured with different weight ratios and different total concentrations of BSs and $\mathrm{PC}$, compared with its solubilizing capacity to other three sterols YC-1, YC-5 and YC-10. In brief, $0.5 \mathrm{~mL}$ of drug-loaded $\mathrm{MM}$ solution was properly diluted in water and then subjected to HPLC analysis equipped with 2000ES Evaporative Light Scattering Detector (Agilent Technologies, Inc., Richardson, TX, USA). The analysis was performed on a Luna C18 column $(150 \times 4.6 \mathrm{~mm}, 5 \mu \mathrm{m}$; Phenomenex, Torrance, CA, USA) at $35^{\circ} \mathrm{C}$. The mobile phase for Triol and $\mathrm{YC}-10$ consisted of methanol and water $(80: 20, \mathrm{v} / \mathrm{v})$, while that for YC-1 and YC-5 was composed of methanol and water $(90: 10, \mathrm{v} / \mathrm{v})$. The flow rate was $1 \mathrm{~mL} / \mathrm{min}$, and the injection volume was $20 \mu \mathrm{L}$. Detection using the evaporative light scattering detector was performed at $90^{\circ} \mathrm{C}$ for the drift tube with the carrier gas flow rate of $2.0 \mathrm{~L} / \mathrm{min}$. The calibration curve was $\lg A=a \lg C+b$, where $A$ is the peak area of the drug, $C$ is the concentration of the drug including 50, 100, 150,200 and $250 \mu \mathrm{g} / \mathrm{mL}, a$ and $b$ are constants but varied in the context of different drugs (for Triol, $a=1.4949$ and $b=3.6713$; for YC-1, $a=1.4644$ and $b=3.8404$; for YC-5, $a=1.4888$ and $b=3.5129$; for YC-10, $a=1.39891$ and $b=3.9752$ ).

\section{Measurement of particle size and zeta potential}

The particle size, polydispersity index and zeta potential of optimized Triol-loaded MM systems were measured by dynamic light scattering (Malvern Zetasizer Nano ZS90; Malvern Instruments Ltd, Malvern, UK) at $25^{\circ} \mathrm{C}$. The samples were measured with proper dilution.

\section{Primary stability study}

Triol-loaded $\mathrm{MM}$ saturated solutions were fabricated by SGC/PC 2:1 (w/w), SBA-Na/PC 2:1 (w/w) and SDC/PC $3: 1(\mathrm{w} / \mathrm{w})$, with the total concentration of BS and PC of $100 \mathrm{mg} / \mathrm{mL}$. The saturated solutions were then stored in sealed vessels at $25^{\circ} \mathrm{C} \pm 2{ }^{\circ} \mathrm{C}$ for 3 months. The solutions were observed for drug precipitation, and drug content was measured after 0,1 and 3 months. The measurement of drug content for a particular system was terminated when a precipitate was observed.

\section{Measuring CMC of drug-loaded MM under accelerated testing conditions}

Triol-loaded MM saturated solutions were prepared as described earlier with reference to the primary stability study. Then, the solutions were kept airtight under accelerated testing conditions $\left(40^{\circ} \mathrm{C}, 75 \%\right.$ relative humidity). A volume of $100 \mu \mathrm{L}$ supernatant was collected on days $0,1,3$ and 5 for SGC/EPC and SGC/SPC systems, on days 0, 1, 2 and 3 for $\mathrm{SDC} / \mathrm{EPC}$ and SDC/SPC systems, and at 0, 6, 12 and $24 \mathrm{~h}$ for SBA-Na/EPC and SBA-Na/SPC systems. The CMCs were analyzed by Fluorescence Steady State System (QM4CW; Photon Technology International Inc., Birmingham, NJ, USA) according to the pyrene $I_{1} / I_{3}$ ratio method ( $I$ is the fluorescence intensity of pyrene). ${ }^{14}$ The pyrene, dissolved in acetone, was added to volumetric flasks followed by removal of acetone in a vacuum chamber. Then, the samples of MM were added to the flasks with final concentrations ranging from $1.0 \times 10^{-3}$ to $1.0 \mathrm{mg} / \mathrm{mL}$, making the final concentration of pyrene to be $4 \times 10^{-7} \mathrm{~mol} / \mathrm{L}$ by dilution with water. The observations were focused on the precipitation during the dilution and whole measurement procedures. The solutions were positioned in a dark room at room temperature for $12 \mathrm{~h}$ before measurements. Fluorescence emission spectra of pyrene were scanned from 350 to $450 \mathrm{~nm}$ with the excitation wavelength of $336 \mathrm{~nm}$ and the emission slit of $5 \mathrm{~nm}$. There are a total of five peaks for pyrene in its fluorescence spectra. The intensities of $I_{1}$ and $I_{3}$ were obtained to calculate the value of $I_{1} / I_{3}$ and were properly fitted by a Boltzmann-type sigmoid with Origin 8.5 software (OriginLab Corporation, Northampton, MA, USA). Boltzmann-type sigmoid is given by the following equation:

$$
y=\frac{A_{1}-A_{2}}{1+e^{\left(x-x_{0}\right) / \Delta x}}+A_{2}
$$

where the variable $y$ corresponds to the pyrene $I_{1} / I_{3}$ ratio value, the independent variable $x$ is the total concentration of the surfactant, $A_{1}$ and $A_{2}$ are the upper and lower limits of the sigmoid, respectively; $x_{0}$ is the center of the sigmoid and $\Delta x$ is directly related to the independent variable occurrence. The $\mathrm{CMC}$ was determined from the mid-point of the sigmoid (Figure S1).

\section{Results and discussion Solubilization of Triol by BS/PC-MM systems \\ Effects of types of BS and $P C$ and weight ratios of $B S$ to $P C$}

Three types of BSs and two types of PC were collocated to prepare six BS/PC-MM systems as shown in Tables 1 and 2. In Table 1, the weight ratios of BS to $\mathrm{PC}$ were increased discretely from 1:1 to $6: 1$, while maintaining the concentration of $\mathrm{PC}$ at $50 \mathrm{mg} / \mathrm{mL}$. As shown in Table 1, all BS/PC-MM systems could remarkably enhance the solubility of Triol. Among them, 
Table I Solubility of Triol in different BS/PC-MM systems with different weight ratios of BS to PC

\begin{tabular}{|c|c|c|c|c|c|c|}
\hline \multirow{2}{*}{$\begin{array}{l}\text { BS/PC } \\
(w / w)\end{array}$} & \multicolumn{6}{|c|}{ Solubility of Triol $(\mathrm{mg} / \mathrm{mL})$} \\
\hline & SGC/EPC & SDC/EPC & SBA-Na/EPC & SGC/SPC & SDC/SPC & SBA-Na/SPC \\
\hline $\mathrm{I}: \mathrm{I}$ & $7.4 \pm 0.6$ & $9.0 \pm 0.5$ & $11.5 \pm 0.8$ & $7.0 \pm 0.3$ & $7.4 \pm 0.1$ & $10.1 \pm 0.3$ \\
\hline I.5:1 & $9.3 \pm 0.5$ & $10.9 \pm 0.8$ & $18.6 \pm 0.7$ & $9.0 \pm 0.1$ & $9.9 \pm 0.1$ & $15.2 \pm 0.1$ \\
\hline $2: 1$ & $10.8 \pm 0.3$ & $11.3 \pm 1.0$ & $21.5 \pm 1.5$ & $11.0 \pm 0.9$ & $10.0 \pm 0.5$ & $22.9 \pm 0.8$ \\
\hline $3: 1$ & $|4.0 \pm 1|$. & $19.3 \pm 1.5$ & $24.7 \pm 1.2$ & $13.2 \pm 1.4$ & $23.2 \pm 0.2$ & $24.8 \pm 0.9$ \\
\hline $4: 1$ & $15.4 \pm 1.3$ & $26.4 \pm 0.9$ & $32.4 \pm 1.8$ & $15.7 \pm 0.5$ & $24.6 \pm 0.7$ & $32.5 \pm 1.3$ \\
\hline $6: 1$ & $24.0 \pm 0.9$ & $28.0 \pm 1.9$ & $32.8 \pm I . I$ & $22.7 \pm 0.7$ & $25.3 \pm 0.5$ & $35.5 \pm 0.3$ \\
\hline
\end{tabular}

Notes: Concentration of PC was fixed at $50 \mathrm{mg} / \mathrm{mL}$; data presented as mean $\pm S D(n=3)$.

Abbreviations: BS, bile salt; BS/PC-MM, bile salt/phosphatidylcholine mixed micelles; EPC, egg phosphatidylcholine; PC, phosphatidylcholine; SBA-Na, swine bile acid-sodium salt; SD, standard deviation; SDC, sodium deoxycholate; SGC, sodium glycocholate; SPC, soya phosphatidylcholine; Triol, Androst-3 $\beta, 5 \alpha, 6 \beta$-triol.

SBA-Na combining with PC achieves the highest solubility of Triol compared to SGC and SDC, regardless of the type of PC. The SDC/PC systems exhibited a slightly higher solubilizing capacity for Triol than the SGC/PC systems, especially at the higher ratio of BS to PC. Moreover, the solubility of Triol in all BS/PC-MM systems rose greatly as the weight ratio of $\mathrm{BS}$ to $\mathrm{PC}$ increased. It was reported that higher $\mathrm{BS} / \mathrm{PC}$ ratio enables BSs to exist around the PC bilayers and also within the interior, which is advantageous for the solubilization of drugs that have similar structures to BSs. ${ }^{2}$ Therefore, in our study, higher solubilizing capacity of SBA-Na/PC could be interpreted by that it possesses more hydroxyl groups and appropriate carboxyl chain length, leading to stronger interaction with drug molecules. Meanwhile, the presence of PC helps to inhibit intermolecular electrostatic repulsion of BS molecules and causes swelling of the micelle volume.

In order to determine the optimized ratio of $\mathrm{BS} / \mathrm{PC}$, different ratios were prepared while keeping the total concentration of BS and PC constant at $100 \mathrm{mg} / \mathrm{mL}$. The results were shown in Table 2 . All six systems reached the highest solubilization capacity for Triol at either $2: 1$ or $3: 1$ ratio of $\mathrm{BS} / \mathrm{PC}$. Therefore, the optimized ratio of $\mathrm{BS} / \mathrm{PC}$ was ultimately determined to be 3:1 for the SDC/PC-MM system and 2:1 for both the SGC/PC-MM and the SBA-Na/ PC-MM systems.

\section{Effects of total concentrations of BS and PC on the solubility of Triol}

The solubility profiles of Triol in different BS/PC-MM systems with their optimized ratios, as mentioned earlier, and varied total concentrations of BS and PC from 50 to $150 \mathrm{mg} /$ $\mathrm{mL}$, are illustrated in Figure 2. The solubilization potential of BS/PC-MM systems increased as the total concentration of BS and PC increased. A linear increase in solubility with increased total concentration was observed for the SGC/ PC-MM system. Also, the solubility curve of SBA-Na/PC and SDC/PC system increased significantly at the concentrations of $75-100 \mathrm{mg} / \mathrm{mL}$ but is followed by a plateau stage or a slight reduction at the concentrations of $100-150 \mathrm{mg} / \mathrm{mL}$. Linear solubility profiles are likely due to increased number of formed micelles with increased concentrations of BS and PC. ${ }^{15}$ On the other hand, the plateau stage of the solubility profiles may account for the solubility limitation of the specific BS and PC in the solvent. Consequently, the total concentration of BS and PC of $100 \mathrm{mg} / \mathrm{mL}$ was applied to prepare MM.

Table 2 Solubility of Triol in different BS/PC-MM systems with different weight ratios of BS to PC at a fixed total concentration

\begin{tabular}{lllllll}
\hline BS/PC & \multicolumn{2}{l}{ Solubility of Triol $(\mathbf{m g} / \mathbf{m L})$} & & & \\
\cline { 2 - 7 }$(\mathbf{w} / \mathbf{w})$ & SGC/EPC & SGC/SPC & SDC/EPC & SDC/SPC & SBA-Na/EPC & SBA-Na/SPC \\
\hline $1: 1$ & $11.9 \pm 0.3$ & $14.7 \pm 0.1$ & $13.9 \pm 0.2$ & $12.9 \pm 0.4$ & $16.3 \pm 0.8$ & $14.5 \pm 0.6$ \\
$1.5: 1$ & $10.5 \pm 0.2$ & $14.2 \pm 0.5$ & $14.9 \pm 0.5$ & $14.7 \pm 0.3$ & $16.5 \pm 0.2$ & $17.4 \pm 0.5$ \\
$2: 1$ & $14.8 \pm 0.3$ & $15.3 \pm 0.3$ & $17.0 \pm 0.4$ & $17.3 \pm 0.2$ & $19.4 \pm 0.6$ & $19.6 \pm 0.9$ \\
$3: 1$ & $13.6 \pm 0.4$ & $13.2 \pm 0.4$ & $17.3 \pm 0.1$ & $17.5 \pm 0.6$ & $16.8 \pm 0.1$ & $15.9 \pm 0.2$ \\
$4: 1$ & $10.7 \pm 0.1$ & $12.9 \pm 0.3$ & $13.2 \pm 0.2$ & $13.8 \pm 0.2$ & $14.9 \pm 0.3$ & $14.4 \pm 0.3$ \\
$6: 1$ & $10.4 \pm 0.1$ & $12.5 \pm 0.1$ & $9.3 \pm 0.2$ & $13.2 \pm 0.4$ & $14.5 \pm 0.3$ & $13.1 \pm 0.3$ \\
\hline
\end{tabular}

Notes: Total concentration of $B S$ and $P C$ was fixed at $100 \mathrm{mg} / \mathrm{mL}$; data presented as mean $\pm \mathrm{SD}(\mathrm{n}=3)$.

Abbreviations: BS, bile salt; BS/PC-MM, bile salt/phosphatidylcholine mixed micelles; EPC, egg phosphatidylcholine; PC, phosphatidylcholine; SGC, sodium glycocholate; SPC, soya phosphatidylcholine; SDC, sodium deoxycholate; SBA-Na, swine bile acid-sodium salt; SD, standard deviation; Triol, Androst-3 $\beta, 5 \alpha, 6 \beta$-triol. 

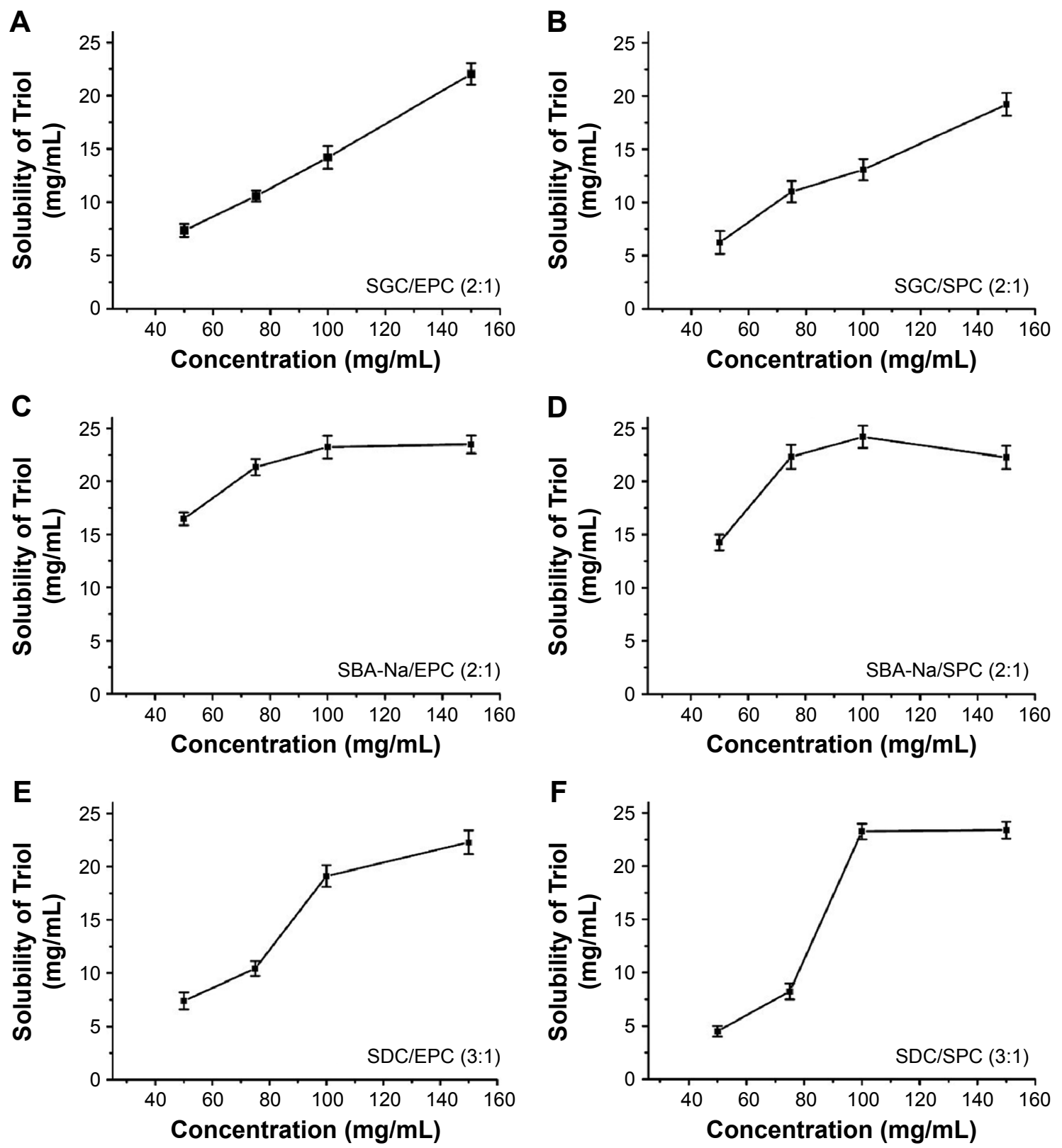

Figure 2 Solubility of Triol in different BS/PC-MM systems with their optimized ratios and varied total concentrations of $B S$ and $P C$ ( $n=3$ ). Notes: (A) SGC/EPC-MM, (B) SGC/SPC-MM, (C) SBA-Na/EPC-MM, (D) SBA-Na/SPC-MM, (E) SDC/EPC-MM and (F) SDC/SPC-MM.

Abbreviations: BS, bile salt; BS/PC-MM, bile salt/phosphatidylcholine mixed micelles; EPC, egg phosphatidylcholine; MM, mixed micelles; PC, phosphatidylcholine; SGC, sodium glycocholate; SPC, soya phosphatidylcholine; SBA-Na, swine bile acid-sodium salt; SDC, sodium deoxycholate; Triol, Androst-3 $\beta, 5 \alpha, 6 \beta$-triol.

\section{Particle size and zeta potential}

The particle size, polydispersity index and zeta potential of the BS/PC-MM systems with optimized ratios and total concentrations of BS and PC are displayed in Table 3. The particle size of all the BS/PC-MM systems ranged from 3.9 to $11.4 \mathrm{~nm}$, which falls within the normal diameter range of micelles. All BS/PC-MM systems were negatively charged, which may be attributable to the BS coverage on the micelles. The repulsion force between the MM facilitates the maintenance of the stability.

\section{Primary stability of Triol-loaded BS/PC-MM systems}

It has been widely accepted that BSs are capable of solubilizing PC to a great extent, forming a clear mixed micellar solution. ${ }^{16}$ Consistently, all Triol-loaded BS/PC-MM systems were transparent in appearance when freshly formulated. However, after stored at $25^{\circ} \mathrm{C}$ for 3 months, drug precipitation appeared in some MM formulations, as shown in Table 4. There was no change in the drug concentration (data not shown) before precipitation appeared. For SBA-Na/PC 
Table 3 Characterization of different Triol-loaded BS/PC-MM systems at their optimized ratios and total concentrations

\begin{tabular}{llll}
\hline $\begin{array}{l}\text { Triol-loaded BS/ } \\
\text { PC-MM systems }\end{array}$ & $\begin{array}{l}\text { Particle } \\
\text { size }(\mathbf{n m})\end{array}$ & PDI & $\begin{array}{l}\text { Zeta potential } \\
(\mathbf{m V})\end{array}$ \\
\hline SGC/EPC & $11.0 \pm 0.7$ & 0.171 & $-20.5 \pm 0.4$ \\
SGC/SPC & $3.9 \pm 0.4$ & 0.228 & $-20.0 \pm 0.3$ \\
SDC/EPC & $7.6 \pm 1.1$ & 0.262 & $-14.0 \pm 1.3$ \\
SDC/SPC & $8.3 \pm 0.3$ & 0.240 & $-14.9 \pm 0.6$ \\
SBA-Na/EPC & $11.4 \pm 0.3$ & 0.211 & $-16.3 \pm 1.0$ \\
SBA-Na/SPC & $7.4 \pm 0.4$ & 0.231 & $-15.8 \pm 1.1$ \\
\hline
\end{tabular}

Note: Data presented as mean \pm SD $(n=3)$.

Abbreviations: BS/PC-MM, bile salt/phosphatidylcholine mixed micelles; EPC, egg phosphatidylcholine; PDI, polydispersity index; SD, standard deviation; SBA-Na, swine bile acid-sodium salt; SDC, sodium deoxycholate; SGC, sodium glycocholate; SPC, soya phosphatidylcholine; Triol, Androst-3 $\beta, 5 \alpha, 6 \beta$-triol.

and SDC/PC systems, drug precipitation appeared at 1 and 3 months after preparation, respectively. However, there was no precipitation observed in SGC/PC system within 3 months. Chemically, higher hydrophilic property of conjugated SGC could decrease the mobility of water molecules near the micellar surface due to hydrogen bonding interaction, which could prevent the micelles from disassociation and further enhance the stability of MM. ${ }^{5}$ Hence, SGC/EPC system with 2:1 ratio in weight and total concentration of $100 \mathrm{mg} / \mathrm{mL}$ was considered as the optimum BS/PC-MM system for further study, based on a comprehensive consideration of solubility, stability and biocompatibility.

\section{The changes of CMC of micelles under accelerated testing conditions}

The drug-loaded MM were found to exhibit different stability performances during the 3 -month storage period. To uncover the reasons behind the stability differences, we employed nuclear magnetic resonance and Raman spectroscopy to assess the interaction between the drug and the micelle but

Table 4 Stability of varied Triol-loaded BS/PC-MM systems at their optimized ratios and total concentrations at $25^{\circ} \mathrm{C} \pm 2^{\circ} \mathrm{C}$

\begin{tabular}{llll}
\hline Triol-loaded BS/ & \multicolumn{2}{l}{ Appearance } & \\
\cline { 2 - 4 } PC-MM systems & Month 0 & Month I & Month 3 \\
\hline SGC/EPC & - & - & - \\
SGC/SPC & - & - & - \\
SDC/EPC & - & - & + \\
SDC/SPC & - & - & + \\
SBA-Na/EPC & - & + & ++ \\
SBA-Na/SPC & - & + & ++ \\
\hline
\end{tabular}

Notes: "-" indicates transparent; "+" indicates precipitation; "++" indicates severe precipitation.

Abbreviations: BS/PC-MM, bile salt/phosphatidylcholine mixed micelles; EPC, egg phosphatidylcholine; SBA-Na, swine bile acid-sodium salt; SDC, sodium deoxycholate; SGC, sodium glycocholate; SPC, soya phosphatidylcholine; Triol, Androst-3 $3,5 \alpha, 6 \beta$-triol. failed because of too much interference from BS possibly due to its structural similarity to Triol. Based on the effect of CMC on solubilizing capacity of micelles, we supposed that $\mathrm{CMC}$ measurements might be of significance for stability evaluation. For time-saving purpose, the measurements were carried out under accelerated testing conditions.

The changes of CMC of drug-loaded BS/PC-MM systems during the accelerated testing are shown in Figure 3 (representative $I_{1} / I_{3}$ fluorescence curves were shown in Figure S2). Both SGC/PC systems exhibited a decreasing CMC (from 0.105 to $0.056 \mathrm{mg} / \mathrm{mL}$ for SGC/EPC and from 0.067 to $0.024 \mathrm{mg} / \mathrm{mL}$ for SGC/SPC) and an ideal transparent appearance. In contrast, $\mathrm{SBA}-\mathrm{Na} / \mathrm{PC}$ and $\mathrm{SDC} / \mathrm{PC}$ systems showed that an increasing $\mathrm{CMC}$ and drug precipitation were observed on the first and third days, respectively. It was interesting to find that the $\mathrm{CMC}$ of $\mathrm{SDC} / \mathrm{PC}$ reached the maximum value on the third day when drug precipitation occurred. Similar results were found in the SBA-Na/PC systems on the first day, in which the change of CMC and the emergence of drug precipitation were earlier than those in SDC/PC-MM. No drug precipitation was observed during the dilution and measurement procedures suggesting that the precipitation was not caused by dilution. Therefore, any variation of $\mathrm{CMC}$ would only be brought about by storage. So we conclude that drug precipitation was highly related to the changes of $\mathrm{CMC}$, suggesting that the variation of $\mathrm{CMC}$ under accelerated conditions could possibly be employed to predict the stability of drug-loaded MM.

Under the accelerated conditions, high temperature might become a perturbing factor to the dynamic process by which $\mathrm{BS}$ and PC molecules form micelles. This disturbing effect may accumulate over time and disrupt the micelles formed in the MM systems. On the other hand, CMC may be positively or negatively affected, depending on the species of BS and $\mathrm{PC}$ in the system. The decreased CMC, as shown in the $\mathrm{SGC} /$ PC system, resulted in an increased number of micelles, thus compensating the micelle-disrupting effect, as stated earlier. However, in SDC/PC and SBA-Na/PC systems, CMC was increased as the storage time proceeded, indicating reduced number of micelles in each system. The diminishing effect caused by CMC increase, combined with the disrupting effect induced by temperature rise, finally led to drug precipitation. Noticeably, the time when CMC significantly increased under accelerated conditions showed a strong correlation to the time when drug precipitation occurred. In brief, the variations of CMC under accelerated conditions were verified to be associated closely with the diverse stability of drug-loaded MM. The increased trend of CMC under accelerated conditions 

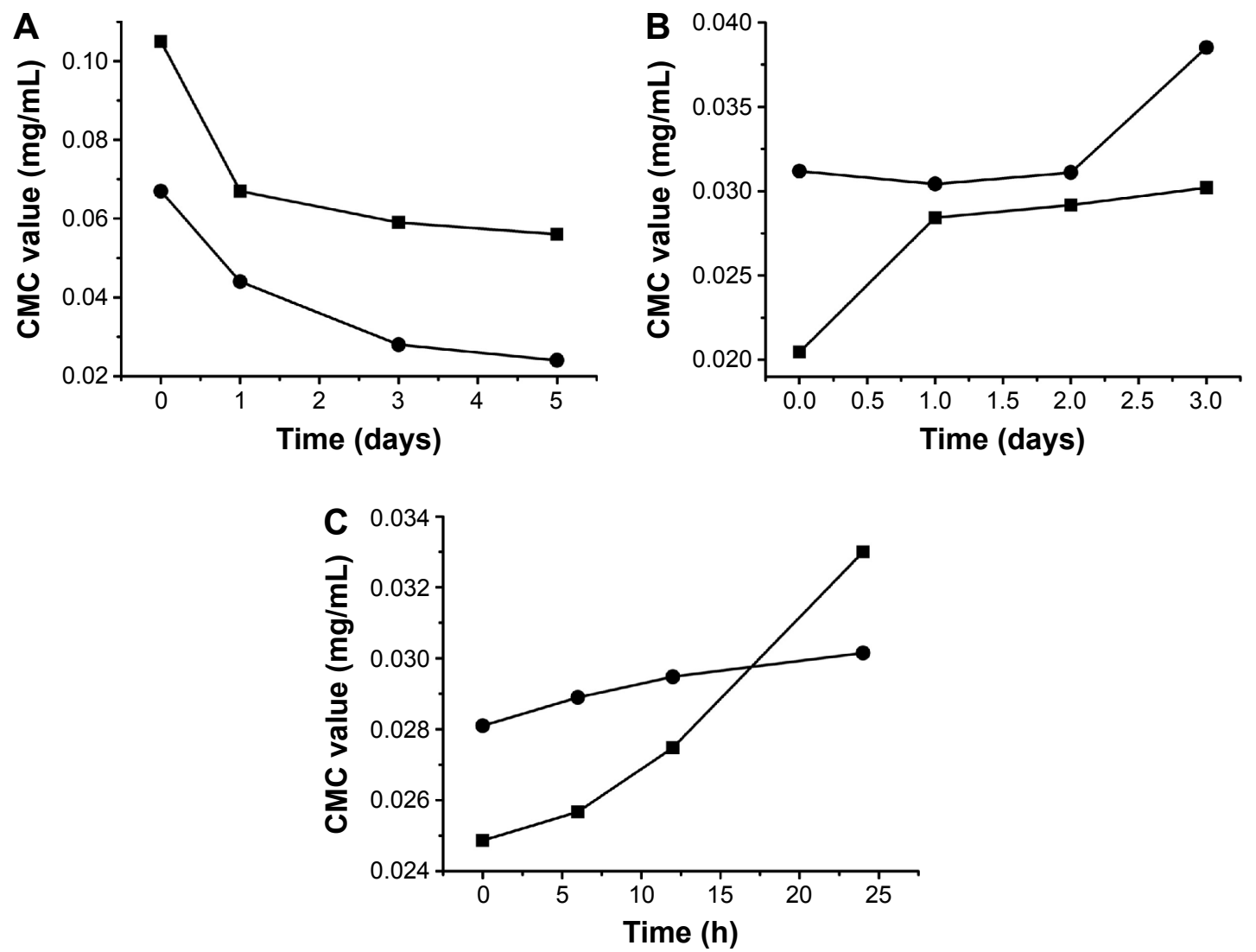

Figure 3 The change of CMC of Triol-loaded BS/PC-MM systems under accelerated testing conditions.

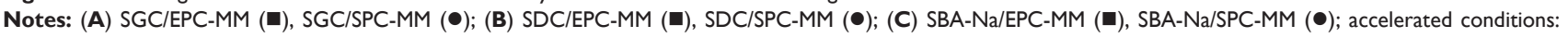
$40^{\circ} \mathrm{C}, 75 \% \mathrm{RH}$.

Abbreviations: CMC, critical micelle concentration; BS/PC-MM, bile salt/phosphatidylcholine mixed micelles; EPC, egg phosphatidylcholine; RH, relative humidity; SBA-Na, swine bile acid-sodium salt; SDC, sodium deoxycholate; SGC, sodium glycocholate; SPC, soya phosphatidylcholine; Triol, Androst-3 $\beta, 5 \alpha, 6 \beta$-triol.

could possibly be a predictive factor to the instability of drug-loaded MM. However, further studies will be needed to reveal the precise correlations between the varied $\mathrm{CMC}$ and stability of BS/PC-MM system during storage.

\section{Solubility of synthesized sterols in the optimized BS/PC-MM system}

To further investigate potential solubilizing capacity of the SGC/PC-MM system, the solubility of three synthesized structural analogs of Triol, that is, YC-1, YC-5 and YC-10, was investigated. The chemical structures and solubility of Triol, YC-1, YC-5 and YC-10 in the optimized formulation are illustrated in Figures 1 and 4, respectively. Solubility of both YC-1 and YC-5 reached up to $23 \mathrm{mg} / \mathrm{mL}$ while were merely 14.2 and $8.3 \mathrm{mg} / \mathrm{mL}$ for Triol and YC-10, respectively. It was concluded that the solubility of different sterols in the optimized SGC/EPC system significantly varied. As mentioned before, the structural similarity between the sterols and BSs could result in more favorable orientation of drug molecules with those of BSs. ${ }^{11}$ This could also account for the discrepancy in solubility of different sterols. YC-1 and YC-5, both having multiple hydroxyl groups and a long alkyl chain, not only can be solubilized in the palisade layer between BS molecules but also can be embedded into the

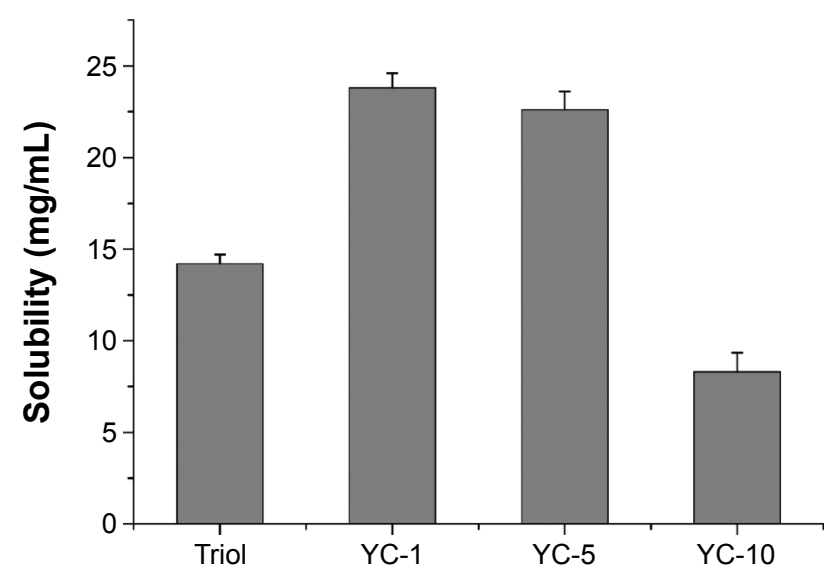

Figure 4 Solubility of synthesized sterols in the optimized SGC/EPC-MM system with ratio in weight $2: 1$ and the total concentration of $100 \mathrm{mg} / \mathrm{mL}(\mathrm{n}=3)$.

Abbreviations: EPC, egg phosphatidylcholine; MM, mixed micelles; SGC, sodium glycocholate; Triol, Androst-3 $\beta, 5 \alpha, 6 \beta$-triol; YC-I, Cholest-24-ene-3 $\beta, 5 \alpha, 6 \beta, 19$ tetrol; YC-5, Cholest-3 $\beta, 5 \alpha, 6 \beta$-triol; YC-10, Androst-2 $\beta, 3 \alpha, 5 \alpha$-trihydroxy-6-one. 
hydrophobic core of the micelles, which results in higher solubility compared with Triol and YC-10. Comparatively, the occurrence of the polar carbonyl group in YC-10 greatly limits its interaction with the lipophilic group of BSs, leading to reduced solubility. Even though the optimized system of SGC/EPC-MM showed very different capacity in solubilizing different sterols, the system gained absolutely elevated solubility for insoluble sterols with good stability, which might be a preferable choice for poorly soluble drugs to be developed into parenteral preparations.

\section{Conclusion}

This study utilized BS/PC-MM systems to solubilize sterol drugs based on the "like dissolves like" theory, in which the BSs possessed similar structures to sterols. We found that a sterol Triol showed efficiently enhanced solubility but diverse stability in different BS/PC-MM systems. Among them, SGC/EPC-MM not only had good solubilizing capacity for Triol but also presented remarkable stability. The dissimilar stability of MM correlated directly with the variety of CMC during storage. The drug-loaded SGC/PC-MM, with reducing $\mathrm{CMC}$, maintains clear in appearance under accelerated testing. However, the increasing CMC of SBA-Na/PC-MM and SDC/PC-MM resulted in drug-precipitating events. Importantly, the time when the variation of CMC happened in different BS/PC-MM systems under accelerated conditions corresponded to the time when the drug precipitation occurred during the storage period. Our findings suggested that the stability of BS/PC-MM system could be simply predicted by the changes of $\mathrm{CMC}$ under accelerated conditions. The strategy is efficient in screening formulations of stable drug-loaded BS/PC-MM system.

\section{Acknowledgments}

This work was supported by Guangdong Innovative and Entrepreneurial Research Team Program (grant number 2013Y104), Leading Talents in Entrepreneurship of Guangzhou (grant number LCY201306) and Leading Talent Project in Science and Technology of Guangzhou Development District (grant number 2013 L-p090). We appreciate $\mathrm{Mr}$ Zhengning $\mathrm{Xu}$ for revising the wording and language.

\section{Disclosure}

The authors report no conflicts of interest in this work.

\section{References}

1. Yan GM, Hu HY, Leng TD, et al, inventor; Guangzhou Cellprotek Pharmaceutical Ltd., assignee. Use of $5 \alpha$-androstane(alkyl)-3 $3,5,6 \beta$ Triol in preparation of neuroprotective drugs. United States patent US 20148809309. 2014 Aug 19.

2. Xu W, Ling P, Zhang T. Polymeric micelles, a promising drug delivery system to enhance bioavailability of poorly water-soluble drugs. J Drug Deliv. 2013;2013:340315.

3. Brajtburg J, Elberg S, Kobayashi GS, Bolard J. Amphotericin B incorporated into egg lecithin-bile salt mixed micelles: molecular and cellular aspects relevant to therapeutic efficacy in experimental mycoses. Antimicrob Agents Chemother. 1994;38(2):300-306.

4. Alkan-Onyuksel H, Ramakrishnan S, Chai HB, Pezzuto JM. A mixed micellar formulation suitable for the parenteral administration of taxol. Pharm Res. 1994;11(2):206-212.

5. Hammad MA, Muller BW. Solubility and stability of lorazepam in bile salt/soya phosphatidylcholine-mixed micelles. Drug Dev Ind Pharm. 1999;25(4):409-417.

6. Hammad MA, Muller BW. Solubility and stability of tetrazepam in mixed micelles. Pharm Acta Helv. 1998;7(1):49-55.

7. Nagata M, Yotsuyanagi T, Ikeda K. Solubilization of vitamin K1 by bile salts and phosphatidylcholine-bile salts mixed micelles. J Pharm Pharmacol. 1988;40(2):85-88.

8. Guo J, Wu T, Ping Q, Chen Y, Shen J, Jiang G. Solubilization and pharmacokinetic behaviors of sodium cholate/lecithin-mixed micelles containing cyclosporine A. Drug Deliv. 2005;12(1):35-39.

9. Roda A, Hofmann AF, Mysels KJ. The influence of bile salt structure on self-association in aqueous solutions. J Biol Chem. 1983;258(10): 6362-6370.

10. Mazer NA, Benedek GB, Carey MC. Quasielastic light-scattering studies of aqueous biliary lipid systems. Mixed micelle formation in bile salt-lecithin solutions. Biochemistry. 1980;19(4):601-615.

11. Hammad MA, Muller BW. Increasing drug solubility by means of bile salt-phosphatidylcholine-based mixed micelles. Eur J Pharm Biopharm. 1998;46(3):361-367.

12. Torchilin VP. Structure and design of polymeric surfactant-based drug delivery systems. J Control Release. 2001;73(2-3):137-172.

13. Lu Y, Park K. Polymeric micelles and alternative nanonized delivery vehicles for poorly soluble drugs. Int J Pharm. 2013;453(1): 198-214.

14. Song X, Jiang Y, Ren CJ, et al. Nimodipine-loaded mixed micelles: formulation, compatibility, pharmacokinetics, and vascular irritability study. Int J Nanomedicine. 2011;7(2):3689-3699.

15. Hammad MA, Müller BW. Solubility and stability of clonazepam in mixed micelles. Int J Pharm. 1998;169(1):55-64.

16. Carey MC. Bile salt structure and phase equilibria in aqueous bile salt and bile salt-lecithin systems. Hepatology. 1984;4(suppl 5): S138-S142. 


\section{Supplementary materials}

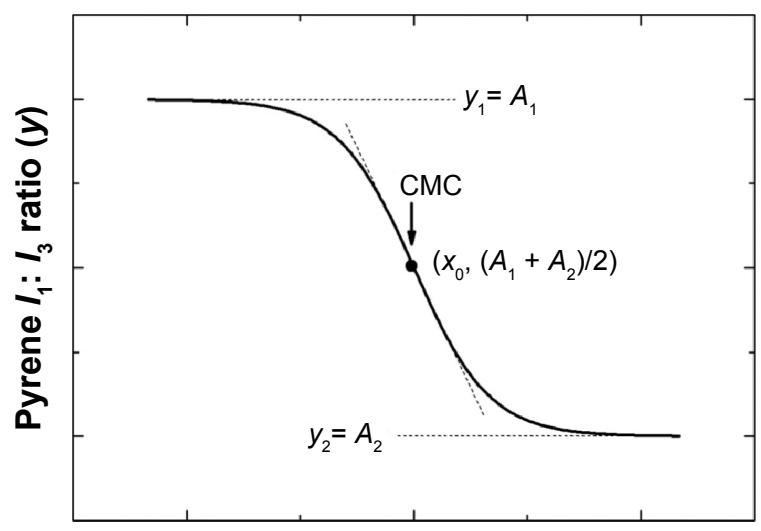

Surfactant concentration $(x)$

Figure SI Plot of the fluorescence of pyrene $I_{1} / I_{3}$ intensity ratio versus concentration of surfactant. The CMC corresponds to the center of the sigmoid.

Notes: The pyrene $I_{1} / I_{3}$ ratio varies in response to the position of pyrene, and $\mathrm{CMC}$ can be measured through the transition of the pyrene $I_{1} / I_{3}$ ratio. Above the $\mathrm{CMC}$, the ratio reaches a roughly constant value because the pyrene is located in the polar environment of water. As the pyrene migrates to a more hydrophobic environment, ie, the micelles, the ratio experiences a rapid decrease and finally reaches a constant value when the pyrene is completely dispersed in the hydrophobic region of micelles. Boltzmanntype sigmoid is given by the equation in the figure, where the variable $y$ corresponds to the pyrene $I_{1} / I_{3}$ ratio value, the independent variable $x$ is the total concentration of the surfactant, $A_{1}$ and $A_{2}$ are the upper and lower limits of the sigmoid, respectively; $x_{0}$ is the center of the sigmoid and $\Delta x$ is directly related to the independent variable occurrence. The CMC was determined from the mid-point of the sigmoid.

Abbreviations: CMC, critical micelle concentration; I, fluorescence intensity of pyrene; $I_{1} I_{3}$, intensity of the third to the first peak of pyrene.
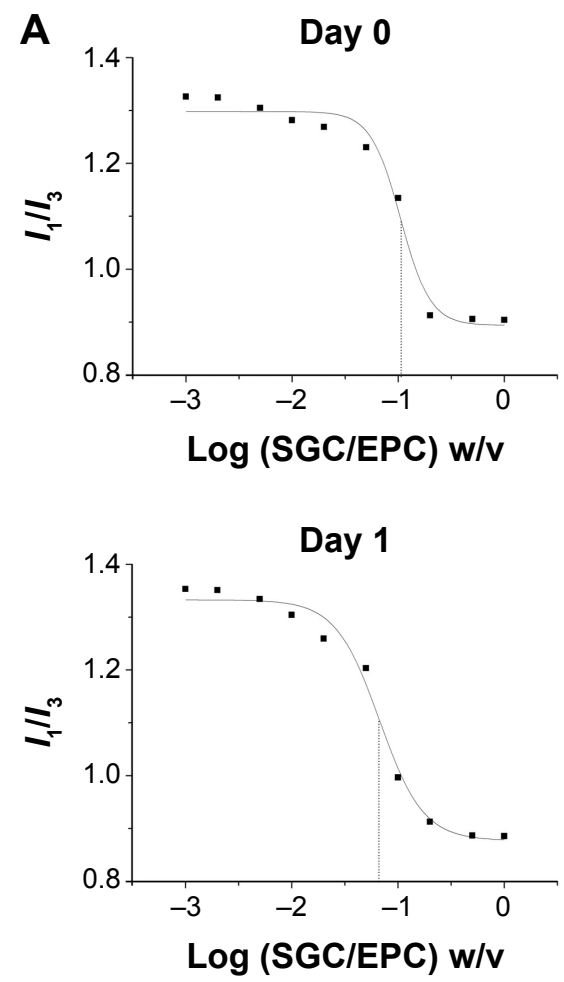

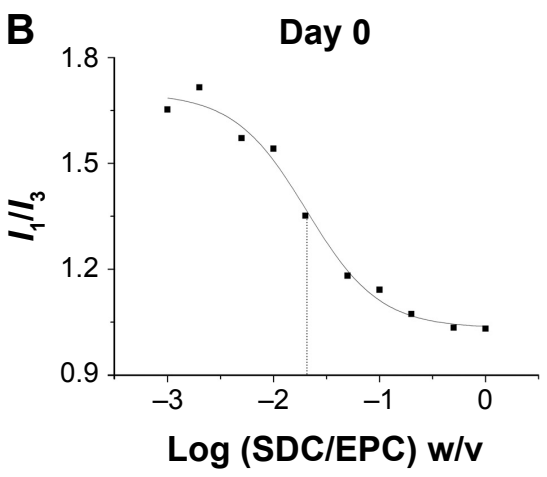

Day 1

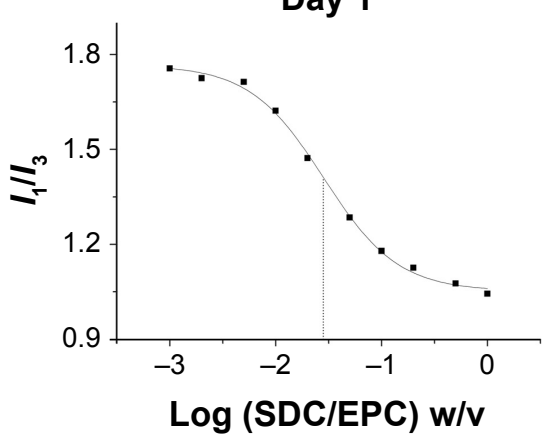

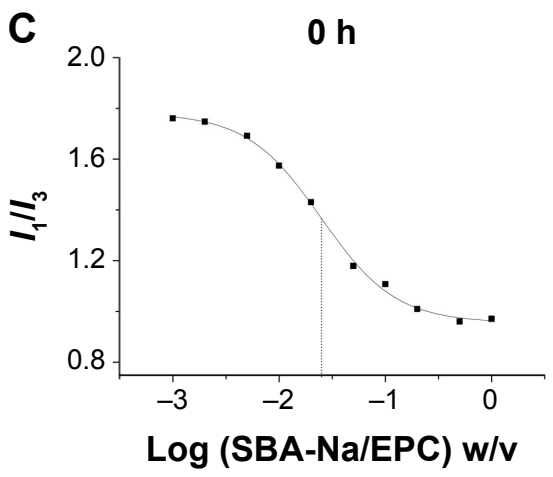

$6 \mathrm{~h}$

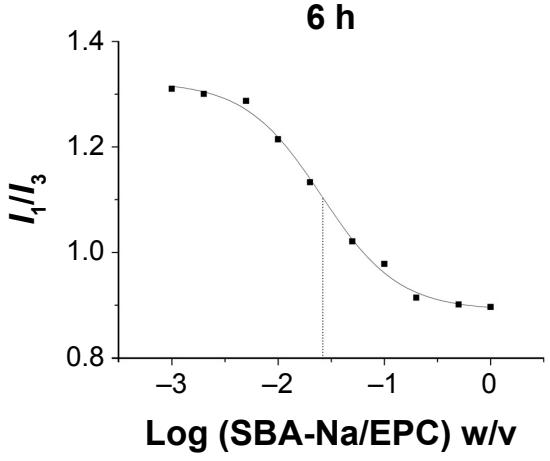

Figure S2 (Continued) 

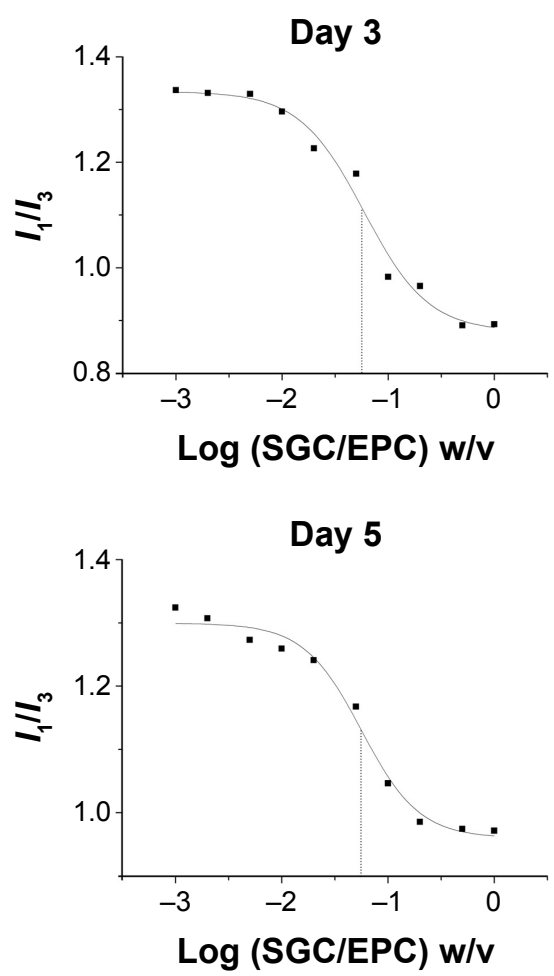
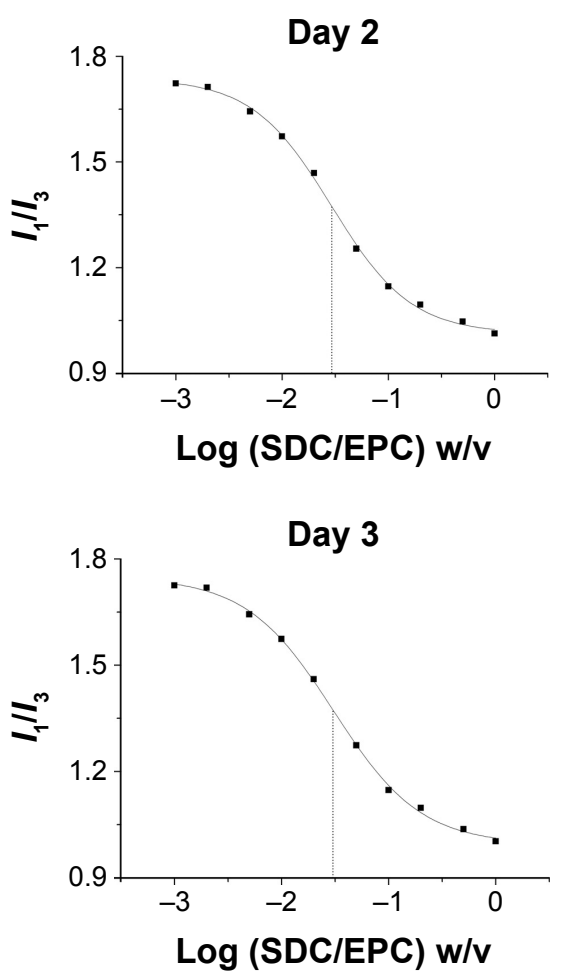

$12 \mathrm{~h}$

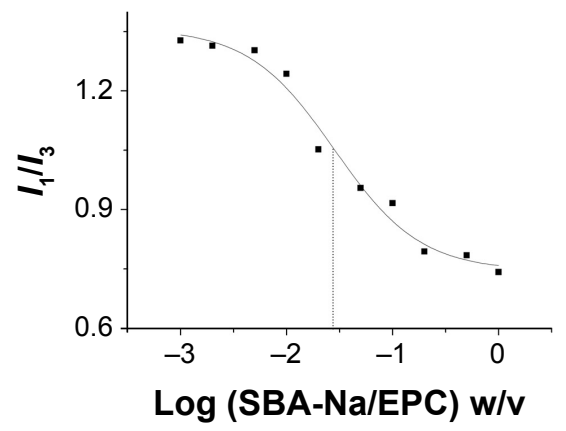

$24 \mathrm{~h}$

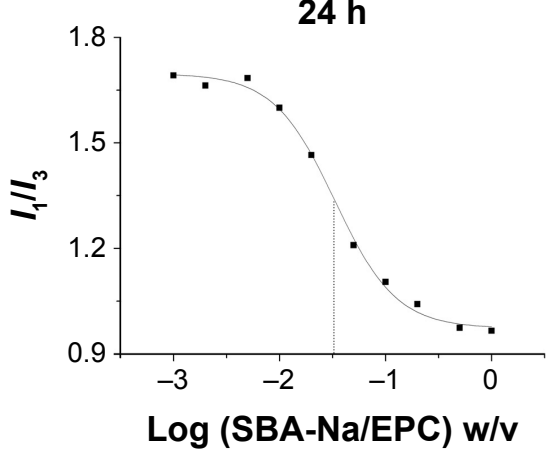

Figure S2 Representative plots of the fluorescence of pyrene $I_{1} / I_{3}$ intensity ratio versus concentration of BS/PC-MM systems under accelerated conditions.

Notes: (A) SGC/EPC-MM, (B) SDC/EPC-MM, (C) SBA-Na/EPC-MM. The pyrene $I_{1} / I_{3}$ ratio data are fitted by a Boltzmann-type sigmoid. The CMC can be obtained from the midpoint of the graph plotted by $I_{1} I_{3}$ versus logarithm of mixed micelles concentration (intersection of the dashed line and $X$-axis).

Abbreviations: BS/PC-MM, bile salt/phosphatidylcholine mixed micelles; CMC, critical micelles concentration; EPC, egg phosphatidylcholine; I, fluorescence intensity of pyrene; $I_{1} / I_{3}$, intensity of the third to the first peak of pyrene; MM, mixed micelles; SBA-Na, swine bile acid-sodium salt; SDC, sodium deoxycholate; SGC, sodium glycocholate; w/v, weight/volume.

\section{Publish your work in this journal}

Drug Design, Development and Therapy is an international, peerreviewed open-access journal that spans the spectrum of drug design and development through to clinical applications. Clinical outcomes, patient safety, and programs for the development and effective, safe, and sustained use of medicines are the features of the journal, which has also been accepted for indexing on PubMed Central. The manuscript management system is completely online and includes a very quick and fair peer-review system, which is all easy to use. Visit http://www.dovepress.com/testimonials.php to read real quotes from published authors. 